\title{
Effect of coffee on blood pressure and electrocardiographic changes in nicotine users
}

\author{
Pradeep Kumar ${ }^{1}$, Dileep Kumar Verma ${ }^{2}$, Jagdish Narayan ${ }^{3}$, Preeti Kanawjia ${ }^{4}$, Archna Ghildiyal ${ }^{5}$ \\ ${ }^{1}$ Professor, Physiology, KG Medical University, Lucknow, ${ }^{2}$ Associate Professor, Physiology, KG Medical University, Lucknow, \\ ${ }^{3}$ Assistant Professor, Physiology, KG Medical University, Lucknow, ${ }^{4}$ Assistant Professor, Physiology, GSVM Medical College, Kanpur, India, \\ ${ }^{5}$ Associate Professor, Physiology, KG Medical University, Lucknow
}

\section{A B S T R A C T}

Objectives: The objectives of this study were to see the effect of coffee on Heart rate Blood pressure and ECG changes in nicotine users. Methods: The study was conducted on 120 volunteers aged 21-40 years and with body mass index (BMI) between $17.3-28.0 \mathrm{~kg} / \mathrm{m}^{2}$. The subjects were divided into two groups: Control $(n=40)$ and Study group $(n=80)$. Results: Observation suggests that increment in blood pressure, recorded in study group after coffee ingestion, was lesser than that of control group. We also observed that there were no significant changes in diastolic blood pressure in any group while the mean arterial pressure was higher in both the groups following coffee ingestion. Conclusion: Coffee ingestion decreases the heart rate with no changes in QTc, hence we concluded that less amount of coffee ingestion may not be harmful.

Key words: Coffee, Nicotine, Blood pressure, QTc interval

\section{INTRODUCTION}

Coffee is one of the most widely consumed beverages in the world. It is the primary source of caffeine in many populations, but also contains several other biologically active components that may have either harmful or beneficial cardiovascular effects. ${ }^{1}$ Caffeine is widely consumed by people of all ages in world as well as in India. ${ }^{2}$ In fact, it is the world's most widely consumed stimulant, $54 \%$ of adults in America consuming on average three cups of coffee per day. ${ }^{3}$ Aside from occurring organically in tea and coffee, caffeine is now an additive in soft drinks, energy drinks, chocolates, potato chips, bottled water, chewing gum and medication which confirms its growing popularity. ${ }^{4}$ There has been an increase in reports of caffeine-intoxication since 1982, with 41 cases of caffeine abuse reported in the United States from 2002 to $2004 .^{5}$ Caffeine induces various acute cardiovascular effects such as an up regulation of circulating catecholamines, leading to increases in systolic and diastolic blood pressure. ${ }^{6}$ An increase in the respiration rate (RR) is the prime effect dependent on the plasma caffeine levels. ${ }^{7}$ Recently there has been an increase in energy drink consumption leading to caffeine abuse, with aggressive marketing and poor awareness on the consequences of high caffeine use. Prolongation or reduction of the electrocardiographic QT interval duration is associated with increased risk of ventricular arrhythmias and sudden cardiac death. ${ }^{8}$ Population studies have also shown associations between smaller increases in QT interval duration and total mortality, cardiovascular mortality, and sudden cardiac death. ${ }^{9}$ Besides genetic disorders and pharmacologic agents that can cause marked prolongation or shortening of the QT interval. ${ }^{10}$

Nicotine, which is the major component of cigarette, affects cardiovascular function and could contribute to cardiovascular diseases. Cigarette smoking accelerates atherosclerosis, producing premature atherosclerosis at epicardial coronary arteries, the aorta, the carotid and cerebral arteries and large arteries in the peripheral circulation. ${ }^{11,12}$ Smoking is also associated with an increased risk of acute cardiovascular events, including acute myocardial infarction, sudden death and stroke. With best of our knowledge none study has been published so for regarding effect of coffee in nicotine user Indian subjects. Therefore in present study we evaluated the blood pressure 
and electrocardiographic changes in nicotine users of north Indian population.

\section{MATERIALS AND METHODS}

\section{Subjects}

The study was approved by the ethics committee of University. The study was conducted on 120 volunteers aged 21-40 years and with body mass index (BMI) between $17.3-28.0 \mathrm{~kg} / \mathrm{m}^{2}$. The subjects were divided into two groups: Control $(\mathrm{n}=40)$ and Study group $(\mathrm{n}=80)$. Exclusion criteria for control group were any dyslipidemia, diabetes, systemic disease, any medication treatment, and smoking of any tobacco products, pregnancy or lactation in the past six months. The nicotine users (tobacco chewer/ smokers) more than five years were included in study group; Exclusion criteria for study group were any dyslipidemia, diabetes, or systemic disease, any medication treatment.

\section{Study protocol}

Each subject was instructed to abstain from any form of exercise for 24 hours before each testing session. Immediately on arrival at the laboratory, the subject rested quietly in a chair.

\section{Recording of Electrocardiogram}

Basal Electrocardiogram (ECG) and blood pressure was recorded for each subject. One cup of coffee were given to subjects of both study and control group. Each cup of caffeinated coffee (CC) contained a $130 \mathrm{mg}$ of caffeine. Computed standard lead-II ECG (CARDIART) was recorded at three minutes before and forty minutes after coffee ingestion. Electrocardiographic measurements like QRS, RR, HR, QT and QTc (Bazzett's formula) intervals of each ECG were automatically measured using dedicated software. Systolic and Diastolic blood pressure were recorded with sphygmomanometer (gold standard).

\section{Statistical analysis}

All data are presented as means \pm SD of the means. Basal pair wise comparisons between the two groups (study and control) were tested for statistical significance using the paired Student's t-test.

\section{RESULTS}

Our data suggests that the heart rate in nicotine users was significantly $(p<0.05)$ higher than control group (Table I). The systolic blood pressure was higher in both groups (study and control) forty minutes following the ingestion of caffeinated coffee. The change in systolic blood pressure in control and study groups was 16\% and $12.5 \%$ respectively higher than its basal value. Observation suggests that increment in blood pressure, recorded in study group after coffee ingestion, was lesser than that of control group.

We also observed that there were no significant changes in diastolic blood pressure in any group while the mean arterial pressure was also higher in both the groups following coffee ingestion.

We also observe that there was decrease in heart rate in both groups 40 minutes after caffeinated coffee ingestion but percentage in heart rate decrease was lesser in study group. The Figure 1 reports the changes in QT and QTc intervals after caffeinated coffee ingestion. Significant changes in the QT duration $(352.00 \pm 15.49$ vs $329.00 \pm 25.14 \mathrm{~ms} \mathrm{P}<0.05)$ was observed forty minutes after coffee ingestion in control group but not in study group $(359.00 \pm 25.49$ vs $374.00 \pm 32.72)$. In fact the QRS and QTc durations did not significantly changes after caffeinated coffee ingestion in either group.

\section{DISCUSSION}

Present study has been planned to elucidate the effect of coffee in control and nicotine user subjects. A cup of coffee can contain 100-150 mg of caffeine, and this may elevate plasma caffeine levels to its peak level. ${ }^{13}$ Caffeine enters all tissue compartment ${ }^{14}$ and through its actions at the adenosine receptor, ${ }^{15}$ it has widespread effects on the central nervous system and all peripheral tissues. Caffeine has been shown to inhibit both A1 and A2 adenosine receptors. ${ }^{16}$ Our observations showed that there was significant difference in basal heart rate in control and study group. The Heart rate in subjects of study group was higher; it may be due to nicotine present in blood of study group. Nicotine binds to nicotinic cholinergic receptors, which are located in the brain, autonomic ganglia, the adrenals and neuromuscular junction ${ }^{17}$ Nicotine works primarily by enhancing the release of various neurotransmitters, including epinephrine, norepinephrine, dopamine, acetylcholine, serotonin, vasopressin and glutamate. ${ }^{18}$ The main cardiovascular effect of nicotine is sympathetic neural stimulation.

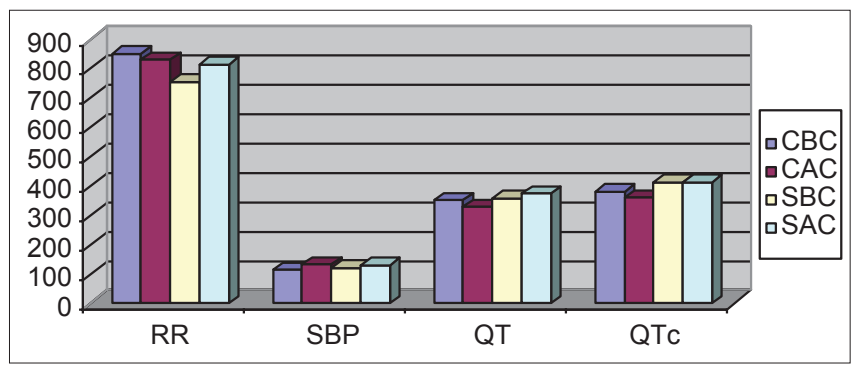

Figure 1: Effect of coffee on various parameters of control and study groups. CBC: Data of control group (before coffee). CAC: Data of Control group (after coffee), SBC: Data of study group (before coffee), SAC: Data of study group (after coffee) 


\begin{tabular}{|c|c|c|c|c|}
\hline \multirow[t]{2}{*}{ Parameter } & \multicolumn{2}{|c|}{ Control group } & \multicolumn{2}{|c|}{ Study group } \\
\hline & $\begin{array}{l}\text { Before coffee } \\
\text { ingestion }\end{array}$ & $\begin{array}{l}\text { After coffee } \\
\text { ingestion }\end{array}$ & $\begin{array}{l}\text { Before coffee } \\
\text { ingestion }\end{array}$ & $\begin{array}{l}\text { After coffee } \\
\text { ingestion }\end{array}$ \\
\hline HR (bpm) & $71.25 \pm 4.96$ & $70.60 \pm 5.06$ & $80.8 \pm 08.34$ & $73.7 \pm 6.46$ \\
\hline $\mathrm{SBP}(\mathrm{mmHg})$ & $114.37 \pm 10.68$ & $132.61 \pm 12.56$ & $120.87 \pm 16.28$ & $130.43 \pm 6.25$ \\
\hline $\mathrm{DBP}(\mathrm{mmHg})$ & $74.50 \pm 9.06$ & $73.50 \pm 8.86$ & $73.50 \pm 8.86$ & $76.89 \pm 7.36$ \\
\hline QRS (ms) & $80.00 \pm 10.54$ & $83.00 \pm 11.59$ & $86.00 \pm 11.73$ & $89.00 \pm 9.94$ \\
\hline $\mathrm{RR}(\mathrm{ms})$ & $852.00 \pm 32.93$ & $832.00 \pm 63.38$ & $756.00 \pm 36.50$ & $815.00 \pm 72.76$ \\
\hline QT (ms) & $352.00 \pm 15.49$ & $329.00 \pm 25.14$ & $359.00 \pm 25.49$ & $374.00 \pm 32.72$ \\
\hline QTc (ms) & $381.40 \pm 15.67$ & $361.50 \pm 34.48$ & $413.00 \pm 37.94$ & $414.10 \pm 22.1$ \\
\hline
\end{tabular}

Our data suggests that the heart rate was decreased in control as well as in study groups while the systolic blood pressure was raised in both the groups. It reveals that the ingested caffeine may not work through the sympathetic system because sympathetic stimulation causes secretion of norepinephrine which has positive chronotropic and as well as positive inotropic effects. Although this preliminary study did not able to identify any mechanism responsible for the increase in systolic blood pressure; it may speculate that caffeine may act via increase in cAMP.

The methylxanthine caffeine is a nonselective adenosine receptor antagonist and phosphodiesterase inhibitor it may leads to increase in the cytosolic calcium. Basal QTc interval was found to be raised in study group showed that nicotine alters the repolarization state.

In fact, it has been recently reported ${ }^{1}$ that caffeine is responsible for a reduced myocardial blood flow response to physical exercise. The possibility also exists that caffeine may influence both left ventricular repolarization and diastolic function modifying the sympathetic/parasympathetic balance; however no hormonal or instrumental measures were considered in this study in order to investigate this hypothesis. We conclude that despite coffee acutely increases systolic and diastolic blood pressure but not the heart rate. Caffeinated coffee does not acutely induce any significant change in the QTc interval duration in the subjects. QTc interval represented the repolarization of myocardium and $\mathrm{K}^{+}$channels set the membrane potential as well as the excitability of most living cells. The $\mathrm{K}^{+}$ions are predominantly responsible for the long QTc.

\section{REFERENCES}

1. Nurminen ML, Niittynen L, Korpela R and Vapaatalo H. Coffee, caffeine and blood pressure: A critical review. Eur J Clin Nutr 1999; 53:831-839.

2. Frary $C D$, Johnson RK and Wang $M Q$. Food sources and intakes of caffeine in the diets of persons in the United States. J Am Diet
Assoc 2005; 105:110-113.

3. Noha HF and Thomas LW. Caffeine and Blood Pressure Response: Sex, Age, and Hormonal Status. Journal of women's health 2010; 19, 6: 1171-1177.

4. Mednick SC, Cai DJ, Kanady J and Drummond SPA. Comparing the benefits of caffeine, naps and placebo on verbal, motor and perceptual memory. Behav Brain Res 2008; 193:79-86.

5. Reissig CJ, Strain EC and Griffiths RR. Caffeinated energy drinks a growing problem. Drug Alcohol Depend 2009; 99, 1-10.

6. Riksen NP, Rongen GA and Smits P. Acute and long-term cardiovascular effects of coffee implications for coronary heart disease. Pharmacol Ther 2009; 121, 185-191.

7. Chou T. Wake up and smell the coffee. Caffeine, coffee and the medical consequences. West J Med 1992;157, 544-553.

8. Priori SG, Schwartz PJ, Napolitano C, Bloise R, Ronchetti E, Grillo $M$, et al. Risk stratification in the long-QT syndrome. N Engl J Med 2003; 348: 1866-1874.

9. Algra A, Tijssen JG, Roelandt JR, Pool J and Lubsen J. QT interval variables from 24 hour electrocardiography and the two year risk of sudden death. Br Heart J 1993; 70: 43-48.

10. Montanez A, Ruskin JN, Hebert PR, Lamas GA and Hennekens $\mathrm{CH}$. Prolonged QTc interval and risks of total and cardiovascular mortality and sudden death in the general population: a review and qualitative overview of the prospective cohort studies. Arch Intern Med 2004; 164: 943-948.

11. McBride PE. The health consequences of smoking: Cardiovascular diseases. Med Clin North Am 1992; 76:333-353.

12. Wilhelmsen L. Coronary heart disease: epidemiology of smoking and intervention studies of smoking. Am Heart J 1988;115:242249.

13. O'Connell SE and Zurzola FJ. Rapid quantitative liquid chromatographic determination of caffeine levels in plasma after oral dosing. J Pharm Sci 1984; 73:1009-1011.

14. Spindel E. Action of the methylxanthines on the pituitary and pituitarydependent hormones. Prog Clin Biol Res 1984; 158: 355- 363.

15. Fredholm BB. Are methylxanthine effects due to antagonism of endogenous adenosine? Trends Pharmacol Sci 1980; 1: 129-132.

16. Smits P, Boekema P, De Abreu R, Thien T and van't Laar A. Evidence for an antagonism between caffeine and adenosine in the human cardiovascular system. J Cardiovasc Pharmacol 1987; 10: 136-143.

17. Benowitz NL. Pharmacologic aspects of cigarette smoking and nicotine addiction. N Engl J Med 1988; 319:1318-1330.

18. Namdar M, Schepis T, Koepfli $P$ and Gaemperli O. Caffeine impairs myocardial blood flow response to physical exercise in patients with coronary artery disease as well as in agematched controls. PLoS One 2009; 22; 4(5):e5665.

Authors Contribution:

PK: Development of hypothesis, DKV \& JN: Collection of data, PK \& AG: Analysis of data.

Source of Support: Nil, Conflict of Interest: None declared. 